\title{
Peripheral nerve field stimulation in medically refractory trigeminal neuralgia attributed to multiple sclerosis
}

\author{
Johann Klein, MD,,3 Timo Siepmann, MD, ${ }^{2,3}$ Gabriele Schackert, MD, ${ }^{1}$ Tjalf Ziemssen, MD, ${ }^{2}$ and \\ Tareq A. Juratli, MD'
}

1Department of Neurosurgery, University Hospital Carl Gustav Carus; ${ }^{2}$ Department of Neurology, University Hospital Carl Gustav Carus, Technische Universität Dresden; and ${ }^{3}$ Dresden International University, Division of Health Care Sciences, Center for Clinical Research and Management Education, Dresden, Germany

OBJECTIVE Case reports and small patient series have suggested peripheral nerve field stimulation (PNFS) as a treatment for refractory trigeminal neuralgia attributed to multiple sclerosis (MS). Here, the authors aimed to assess the effects of this technique on long-term pain severity.

METHODS Data were prospectively collected on patients with refractory trigeminal neuralgia attributed to MS who underwent PNFS between July 2013 and August 2017 at the authors' neurosurgical department. Patients were evaluated before and after the first treatment as well as at follow-up at least twice a year. Patients underwent assessment of their pain severity using the Barrow Neurological Institute (BNI) Scale before treatment and at follow-up and were questioned about adverse events following cranial MRI performed after implantation of a permanent PNFS system.

RESULTS Eight patients ( 3 women) underwent PNFS trials and their median age was 61 years (IQR $73.75-46.5$ years). Seven patients proceeded to permanent implantation of the stimulation system. At a median follow-up of 33 months (IQR 42 - 24 months), pain severity decreased from baseline to the last follow-up (BNI score decrease from $V$ [IQR V - V] to III [IQR V - III], p = 0.054). Four patients experienced long-lasting benefit (at 48, 33, 24, and 15 months' follow-up, respectively), while in 3 patients the treatment eventually failed after an initially successful period. One patient had an infection, requiring system removal and subsequent reimplantation. No other complications occurred. No adverse events were noted in the patients undergoing MRI postimplantation.

CONCLUSIONS This analysis indicates a possibly beneficial long-term effect of PNFS on refractory trigeminal neuralgia attributed to MS in some patients.

https://thejns.org/doi/abs/10.3171/2019.12.JNS192261

KEYWORDS trigeminal neuralgia; facial pain; neuropathic pain; neuromodulation; stimulation

$\mathrm{T}$

RIGEMINAL neuropathic pain occurs more often in patients with multiple sclerosis (MS) than in the general population with reported incidence rates of $1.9 \%-6.3 \% .16,32,37$ The symptoms can be indistinguishable from those in classic trigeminal neuralgia (CTN), with paroxysmal, short-lived, stabbing or sharp pain attacks in the distribution of one or more trigeminal nerve branches, which can be triggered by talking, chewing, or brushing teeth. ${ }^{44}$ Yet, while CTN is caused by neurovascular contact, the most likely reason for trigeminal neuropathic pain in MS is demyelinating plaque in the trigeminal root entry zone or the intrapontine trigeminal primary afferents..$^{10}$

The first-line symptomatic treatment for trigeminal neuralgia in MS is the same as in CTN, with carbamazepine the initial drug of choice and oxcarbazepine, lamotrigine, gabapentin, and baclofen constituting secondline treatment. ${ }^{44}$ While microvascular decompression is a viable and established surgical therapy with high success rates in medically refractory cases of $\mathrm{CTN},{ }^{4}$ such therapy is rendered controversial in trigeminal neuralgia attributed to MS given its different etiology, even if a neurovascular contact is additionally present. ${ }^{2,8,13}$ Other therapies are mostly destructive procedures, such as rhizotomy by radiofrequency or glycerol, radiosurgery, balloon compression, or open partial rhizotomy (Dandy procedure). These procedures can be effective; however, they are associated

ABBREVIATIONS BNI = Barrow Neurological Institute; CTN = classic trigeminal neuralgia; MS = multiple sclerosis; PNFS = peripheral nerve field stimulation; RRMS = relapsing-remitting $\mathrm{MS}$. 
with potentially permanent complications such as hypesthesia. 5, $7,25,28,39$ Alternatively, spinal cord stimulation, motor cortex stimulation, and deep brain stimulation have been used for the treatment of refractory facial pain. ${ }^{6,33,40}$

Peripheral nerve field stimulation (PNFS) is a simple surgical procedure in which one or more electrodes are implanted subcutaneously into the painful area and connected to an implantable stimulator. An electric current is then produced and applied via electrodes. Controlled research has shown the technique's efficacy in alleviating low-back pain ${ }^{21,27}$ as well as different headache syndromes. ${ }^{11,24,29,35}$ Neuropathic facial pain is among the conditions that seem amenable to PNFS, ${ }^{12,18,36}$ and interest in this procedure for patients suffering from refractory trigeminal neuropathic pain syndromes has been increasing. ${ }^{14,17,19}$ Patients with MS present particular challenges in the neuromodulatory treatment of trigeminal neuropathic pain, including their need for regular MRI, which can be disturbed by the stimulation device.

We aimed to identify a cohort of MS patients receiving PNFS for trigeminal neuralgia and assess the effects of stimulation on long-term pain severity as well as the impact on the tolerability of MRI.

\section{Methods}

\section{Study Design and Population}

After electrode implantation in our first $2 \mathrm{MS}$ patients, we established prospective data collection for patients with trigeminal neuralgia attributed to MS. In the present retrospective analysis, we included only the patients who had undergone PNFS in the period between July 2013 and August 2017 in our neurosurgical department and were over the age of 18 years, had previously received specialist neurological and pain therapeutic treatment, and were considered to have medically refractory disease or had suffered from intolerable medication-related adverse effects such as severe gait ataxia, confusion, or hyponatremia. These patients were routinely informed about percutaneous methods as treatment options before consenting to a PNFS trial. The patients were followed up in our outpatient department. Additionally, their medical records were reviewed, and the data collection was completed with repeated telephone interviews.

\section{Surgical Procedure}

A trial stimulation was performed after preoperative marking of the painful area and the planned position of the electrode tip. Implantation of the electrode was performed in a sterile surgical fashion with the patient under either local anesthesia or general anesthesia, depending on their preference. If two trigeminal branches were affected, two electrodes were implanted. The lead was externalized and connected to an external pulse generator, which allowed the patient to adjust the stimulation amplitude and test the PNFS system at home. The trial was considered successful if at least a $50 \%$ improvement in self-reported pain intensity and/or frequency of attacks was achieved and both the patient and the physician explicitly favored definitive implantation. In these cases, a permanent system was implanted while the patient was under general anesthesia. We have used Vectris SureScan MRI leads and PrimeAdvanced SureScan MRI impulse generators since 2015, and Pisces Quad Plus leads and PrimeAdvanced impulse generators were used in 2 patients before 2015 (all Medtronic). The impulse generators were programmed on the 1st day after surgery, and patients were trained in adjusting the amplitude according to their needs. The goal was to induce slight, pleasant paresthesia in the affected area. Patients were advised not to turn off the stimulation completely. The usual settings on first programming were $40-80 \mathrm{~Hz}, 450 \mu \mathrm{sec}$, and very variable amplitudes depending on the individual patient's perception. All contacts were activated with alternating anode-cathode order with adjustments if required. If necessary, the settings were corrected during outpatient contacts. A more detailed description of the implantation procedure has been provided elsewhere. ${ }^{19}$

\section{Evaluation of Patients}

Routine follow-up controls were performed twice a year in the neurosurgical pain outpatient clinic. Pre- and postoperative pain characteristics, medication use, and adverse effects were evaluated. Additionally, patients were contacted by telephone by one of the authors (J.K.) to gather missing or updated information on pain perception, medication use, and possible adverse events. Self-reported pain intensity was rated according to the Barrow Neurological Institute (BNI) pain intensity score, a scale ranging from I (no pain, no medication) to $\mathrm{V}$ (severe pain, no relief). ${ }^{34}$

\section{Statistical Analysis}

For statistical analysis of the BNI score, we applied a Wilcoxon signed-rank test in JASP version 0.9 (JASP Team). The line graph was created in Microsoft Excel 2010 (Microsoft Corp.).

\section{Ethical Considerations}

All patients gave written informed consent for the use and publication of their data. The study was approved by the ethics commission at the Technical University Dresden.

\section{Results}

Eight consecutive patients underwent PNFS testing for trigeminal neuralgia attributed to MS at our institution. The cohort comprised 5 men and 3 women, whose median age was 61 years (IQR 73.75 - 46.5 years) and median symptom duration of facial pain was 11 years (IQR 13.75 - 5 years). In 1 case, microvascular decompression had been performed without success. Two patients had received percutaneous treatment in the past without lasting relief.

All 8 patients, all of whom had undergone test stimulation, experienced a significant response with over $50 \%$ pain reduction and thus were considered for definitive implantation. A young man died of progressive multifocal leukoencephalopathy before implantation of the permanent PNFS system was scheduled; all remaining patients received the stimulation system. A total of 11 electrodes 
TABLE 1. Overview of the patient cohort including outcome data

\begin{tabular}{|c|c|c|c|c|c|c|c|c|c|c|}
\hline Dx & Area & $\begin{array}{c}\text { MS } \\
\text { Duration } \\
\text { (yrs) }\end{array}$ & $\begin{array}{c}\text { TN } \\
\text { Duration } \\
\text { (yrs) }\end{array}$ & $\begin{array}{c}\text { Preop } \\
\text { BNI } \\
\text { Score }\end{array}$ & $\begin{array}{c}\text { FU } \\
\text { BNI } \\
\text { Score }\end{array}$ & $\begin{array}{c}\text { FU } \\
(\mathrm{mos})\end{array}$ & $\begin{array}{l}\text { Preop Analgesics } \\
\text { (mg) }\end{array}$ & $\begin{array}{l}\text { Last FU Analgesics } \\
\text { (mg) }\end{array}$ & Preop MS Therapy & $\begin{array}{l}\text { PNFS } \\
\text { AEs }\end{array}$ \\
\hline RRMS & Lt V3 & 18 & 13 & V & 1 & 48 & $\begin{array}{c}\text { PHT } 300, \text { BAC } 62.5 \\
\text { CBZ } 800, \text { HYD } 8\end{array}$ & None & Interferon beta & None \\
\hline SPMS & Lt V2+3 & 37 & 17 & V & V & 42 & $\begin{array}{l}\text { GBP 2400, OXC } \\
1800\end{array}$ & $\begin{array}{l}\text { BAC 10, OXC 600, } \\
\text { LTG } 225, \text { OXY } 40\end{array}$ & Fampridine & None \\
\hline SPMS & Rt V2+3 & 29 & 5 & V & III & 33 & $\begin{array}{c}\text { GBP 2000, LTG } \\
275, \text { BAC } 30\end{array}$ & $\begin{array}{l}\text { OXC when needed } \\
\text { (once in 3-4 days) }\end{array}$ & Fampridine & Infection \\
\hline RRMS & Lt V2+3 & NA & 2.5 & V & IV & 36 & $\begin{array}{l}\text { BAC } 30, \text { LTG } 275 \\
\text { GBP } 2000\end{array}$ & CBZ 2100, LTG 100 & Fingolimod & None \\
\hline RRMS & Rt V3, It V2 & 13 & 11 & V & V & 28 & $\begin{array}{l}\text { BAC 50, GBP } 1800, \\
\text { CBZ } 600\end{array}$ & $\begin{array}{l}\text { BAC 75, GBP 2000, } \\
\text { PHT } 300\end{array}$ & Dimethyl fumarate & None \\
\hline SPMS & Lt V3 & NA & NA & V & III & 24 & CBZ 600 & OXC 1200 & $\begin{array}{l}\text { Siponimod or placebo } \\
\text { (EXPAND trial) }\end{array}$ & None \\
\hline SPMS & Rt V3 & 23 & 14 & IV & III & 15 & OXC 1500 & OXC 900, LTG 125 & None & None \\
\hline
\end{tabular}

$\mathrm{AE}=$ adverse event; $\mathrm{BAC}=$ baclofen; $\mathrm{CBZ}=$ carbamazepine; $\mathrm{Dx}=$ diagnosis; $\mathrm{FU}=$ follow-up; $\mathrm{GBP}=$ gabapentin; $\mathrm{HYD}=$ hydromorphone; $\mathrm{LTG}=$ lamotrigine; $\mathrm{NA}=$ not available; OXC = oxcarbazepine; $\mathrm{OXY}=$ oxycodone; $\mathrm{PHT}$ = phenytoin; SPMS = secondary progressive MS; TN = trigeminal neuralgia.

were implanted in 7 patients (Table 1). The patients were scheduled for follow-up visits once every 6 months. Additional visits took place as needed. The median follow-up time was 33 months (IQR $42-24$ months).

Shortly after implantation of the definitive system, all patients had marked self-reported improvement in their trigeminal neuropathic pain, and in 5 cases, medication could be reduced (Table 1). In the long term, symptom development was highly variable, with 4 patients experiencing some lasting improvement upon the latest followup and 3 patients suffering relapses of their trigeminal neuralgia to a BNI score of IV or $\mathrm{V}$, corresponding to treatment failure. The time to treatment failure was 16 , 25 , and 36 months, respectively. Pain severity decreased from baseline to the last follow-up (median BNI score decrease from V [IQR V - V] to III [IQR V - III], p = 0.054). Figure 1 provides a representation of symptom development from baseline to the last follow-up. Two patients later received high cervical spinal cord stimulation as a salvage procedure after experiencing no relief from PNFS - both, again, without lasting success. None of the patients received percutaneous treatment since implanta-

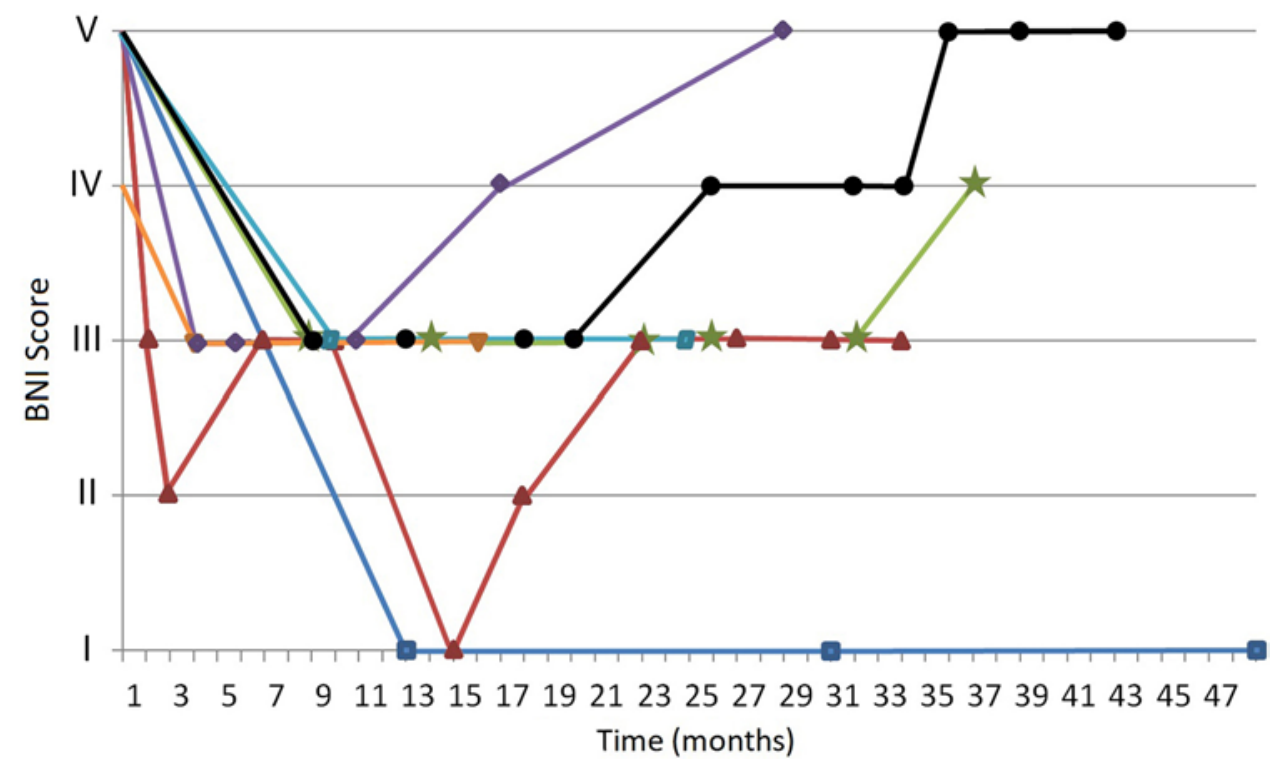

FIG. 1. Development of the BNI score in 7 patients with trigeminal neuralgia attributed to MS after the beginning of PNFS. The data are presented as individual BNI scores ( $y$-axis) at different time points expressed in months ( $x$-axis) following the implantation. Each line represents one patient, and the symbols mark the time points of the respective follow-up. Figure is available in color online only. 
tion of the PNFS system either because a rhizotomy had already been attempted in the past or because the patients did not consent.

No patient experienced stimulation-dependent adverse effects. One patient suffered from an infection of the stimulation system, which had to be explanted and was reimplanted 3 months later. No pain at the stimulator site, electrode dislocation, or other mechanical complications arose.

At least 4 of the patients underwent MRI studies after implantation of the stimulation system, which were performed at $1.5 \mathrm{~T}$ without any special adjustments apart from possible reduction of the specific absorption rate at the radiologist's discretion. The stimulators were switched into the MRI mode or turned off for the time of the scan and turned back on afterward. The scans were uneventful, and the quality of the MR images was without artifacts. No patient reported heating of the electrodes or any dysfunction. In the 4 patients whose MR images are available to us, no changes in the MS lesions occurred during the study period.

\section{Discussion}

In our cohort, PNFS led to a long-term decrease in the pain level in 4 of 7 patients with refractory trigeminal neuralgia attributed to MS. Although this result may indicate a potentially beneficial effect of the procedure, our findings need to be interpreted with care given the lack of a control group.

We observed a high initial response, with all patients reporting a notable decrease in pain and most patients reducing their medication after implantation. One patient experienced remission and did not require any specific medication at the latest follow-up. In the long term, however, 3 of the 7 patients had a notable deterioration and did not seem to obtain any benefit from stimulation. These treatment failures occurred at 16, 25, and 36 months, respectively: an elderly man with secondary progressive MS and a 17-year history of neuropathic facial pain at the time of surgery, a middle-aged woman with relapsing-remitting MS (RRMS) and an 11-year history of neuropathic pain, and another middle-aged woman with RRMS who had had a 2.5-year history of pain. The treatment failures were not related to the progression or a relapse of the MS. While 5 of the 7 patients could cut down on their medication after system implantation, most of them needed to increase their drug intake after some time. These dynamics are not reflected by the BNI score because of relative imprecision: a score of III, meaning "some pain, adequately controlled with medication," allows for a broad spectrum of states including very little or a high amount of medication to achieve acceptable pain control.

One can only hypothesize about the reason for the apparent decline in the stimulation effect over time. Regarded skeptically, the initial response may be indicative of a placebo effect, which chronic pain patients are prone to. ${ }^{9,20}$ Yet, given our experience, including a relapse 2 years after system implantation, which entailed an emergency admission and turned out to be caused by a discharged implantable pulse generator in a patient not included in this series (unpublished data), we believe that a placebo effect is unlikely to be the sole explanation for the clear improvement in our patients. Also, the effectiveness of subcutaneous stimulation has been demonstrated in other studies, including double-blind settings. ${ }^{11}$ As for the reduction in the treatment effect, one possible reason is progress of the underlying pain syndrome. Moreover, placement of the electrodes and/or the stimulation itself may have led to the development of scarring in the surrounding subcutaneous tissue, which, in turn, may have impeded the distribution of electrical current toward small fiber nerve branches. It must be noted, however, that various treatments have shown a similar decline in effectiveness over time, underlining the difficulties in treating refractory trigeminal neuralgia in MS patients. ${ }^{22,31}$

The usefulness of PNFS for patients with trigeminal neuralgia attributed to MS needs to be carefully evaluated. While our excitement about the initial success has been tempered by experience, our results indicate that 4 of 7 patients still had some benefit in the long term. At $p$ $=0.054$, the reduction in the BNI score bordered on statistical significance despite the small number of patients. Given the arduous nature of the pain syndrome and the multitude of failed therapies that led to the consideration of PNFS, this finding must be regarded as a notable result. Compared to that in our previous publication, ${ }^{19}$ we found a markedly reduced rate of adverse events. With only one infection and no other side effects, the risk profile seems to be favorable and to support the role of PNFS as a treatment option.

PNFS has been described as a treatment alternative for refractory facial pain in various case reports and case series including etiologies such as postherpetic ${ }^{12,15,17,18,38}$ and posttraumatic ${ }^{3,15,18,23,38}$ origins as well as CTN, MS-associated trigeminal neuralgia, and atypical facial pain or persistent idiopathic facial pain. . $^{15,18,19,26,43}$ Table 2 gives an overview of these cases. Most studies had a mean followup of less than 2 years, and not all gave sufficient detail about the conditions treated. In some cases, the pain syndromes were not even clearly defined..$^{14,41,42}$ These shortcomings indicate a risk of bias. In our study, we found a high initial treatment response in all patients with significantly less success at the long-term follow-up. A shorter follow-up time could have falsely yielded more positive results.

As MRI controls are of paramount importance for the management of MS, the treatment should not interfere with the diagnostics. Thus, we chose Medtronic Vectris SureScan MRI leads - which were originally designed for epidural spinal cord stimulation-and since 2015, we have used Medtronic PrimeAdvanced SureScan MRI impulse generators, as these are eligible for full-body MRI. As no MRI-related complications arose, we are encouraged in referring patients with PNFS systems for MRI at $1.5 \mathrm{~T}$ despite being an off-label use.

Our study suffers from the limitations of an uncontrolled observational single-center study. Although we standardized outcome parameters (e.g., not considering the numeric rating scale, as we found it to be unreliable for neuropathic facial pain) and adhered to a regular followup routine, we cannot exclude recall bias and regression 
TABLE 2. Overview of case series reporting on PNFS in patients with facial pain

\begin{tabular}{|c|c|c|c|c|c|}
\hline Authors \& Year & No. w/ IPG & Etiology & FU & Outcome & Complications \\
\hline Dunteman, 2002 & 2 & $\mathrm{PH}$ & 3 yrs & $\begin{array}{l}\text { Approximately } 50 \% \\
\text { improvement }\end{array}$ & None \\
\hline $\begin{array}{l}\text { Johnson \& Bur- } \\
\text { chiel, } 2004\end{array}$ & 10 & PT, PH, AFP & $2 \mathrm{yrs}$ & $\begin{array}{l}70 \% \text { of pts } w />50 \% \text { pain } \\
\text { relief }\end{array}$ & $3 / 10$ ( 2 wound breakdown, 1 short extension cable) \\
\hline $\begin{array}{l}\text { Slavin \& Wess, } \\
2005\end{array}$ & 9 & Not reported & 35 mos & $\begin{array}{l}73 \% \text { of pts } w />50 \% \text { pain } \\
\text { relief }\end{array}$ & 2/9 (1 loss of effect, 1 skin erosion) \\
\hline $\begin{array}{l}\text { Narouze \& Kapural, } \\
\quad 2007\end{array}$ & 1 & $\mathrm{CH}$ & 14 mos & Remission & None \\
\hline $\begin{array}{l}\text { Asensio-Samper et } \\
\text { al., } 2008\end{array}$ & 1 & PT & 4 yrs & $\begin{array}{l}\text { VAS score reduction from } \\
10 \text { to } 2\end{array}$ & None \\
\hline Amin et al., 2008 & 10 & SN & 30 wks & $\begin{array}{l}\text { Average VAS score reduc- } \\
\text { tion from } 7.5 \text { to } 3.5\end{array}$ & 3/10 (2 superficial infection, 1 wound breakdown) \\
\hline $\begin{array}{l}\text { Yakovlev \& Resch, } \\
\quad 2010\end{array}$ & 1 & AFP & $12 \mathrm{mos}$ & Excellent & None \\
\hline Stidd et al., 2012 & 3 & PT, PH & $\begin{array}{r}\text { Mean } 18.7 \text { mos } \\
\quad \text { (range 6-27) }\end{array}$ & $\begin{array}{l}\text { Mean } 87 \% \text { pain relief } \\
\quad \text { (range } 60 \%-100 \%)\end{array}$ & 1/3 (occasional HA) \\
\hline Lenchig et al., 2012 & 1 & PT & 3 mos & $>50 \%$ pain relief & None \\
\hline Feletti et al., 2013 & 6 & PIFP, PT, PS, PH & $\begin{array}{l}\text { Mean } 17 \text { mos } \\
\quad \text { (range } 0-32 \text { ) }\end{array}$ & $\begin{array}{l}\text { Mean pain score reduction } \\
\text { from } 10 \text { to } 2.7\end{array}$ & $2 / 6$ (1 traumatic rupture, 1 infection) \\
\hline Verrills et al., 2014 & 10 & HA disorders & $\begin{array}{l}\text { Average } 12.9 \\
\text { mos }\end{array}$ & $\begin{array}{l}68 \% \text { of pts } w />50 \% \text { pain } \\
\text { relief }\end{array}$ & $\begin{array}{l}\text { 10/10 including occipital nerve stimulation ( } 7 \\
\text { hardware erosion, } 1 \text { hardware failure, } 1 \text { lead } \\
\text { migration, } 1 \text { short cable) }\end{array}$ \\
\hline Ellis et al., 2015 & 15 & $\begin{array}{l}\text { HA, TNP, PH, } \\
\text { TN, SN, TDP, } \\
\text { TMJ disorders }\end{array}$ & $\begin{array}{l}\text { Average } 15 \\
\text { mos }\end{array}$ & $\begin{array}{l}73 \% \text { of pts w/ improve- } \\
\text { ment }\end{array}$ & $\begin{array}{l}\text { 12/15 including trial electrode implantations ( } 7 \\
\text { electrode malfunction, } 1 \text { extension wire malfunc- } \\
\text { tion, } 1 \text { IPG pocket pain, } 3 \text { inadequate pain relief) }\end{array}$ \\
\hline Klein et al., 2016 & 8 & CTN, MS, PIFP & $\begin{array}{r}\text { Mean } 11.3 \text { mos } \\
\quad \text { (range } 5-28)\end{array}$ & $\begin{array}{l}\text { Mean } 91 \% \text { pain relief } \\
\quad \text { (range } 57 \%-100 \%)\end{array}$ & $\begin{array}{l}\text { 3/8 (1 electrode defect, } 1 \text { wound breakdown, } 1 \text { IPG } \\
\text { dislocation) }\end{array}$ \\
\hline Jakobs et al., 2016 & 6 & $\mathrm{PH}, \mathrm{CTN}$ & $\begin{array}{l}\text { Average } 15.2 \\
\text { mos }\end{array}$ & $\begin{array}{l}\text { Mean } 88 \% \text { pain relief } \\
\quad \text { (range } 75 \%-100 \%)\end{array}$ & $3 / 6$ (1 infection, 2 muscle stimulation) \\
\hline Weiner et al., 2017 & 10 & $\begin{array}{l}\text { Chronic craniofa- } \\
\text { cial pain }\end{array}$ & 4 wks & $\begin{array}{l}\text { Mean } 91 \% \text { pain relief } \\
\quad \text { (range } 47.7 \%-100 \%)\end{array}$ & None \\
\hline $\begin{array}{l}\text { McMahon et al., } \\
\text { 2019* }\end{array}$ & 17 & PIFP & Mean 10 mos & Mean $97 \%$ pain reduction $†$ & $\begin{array}{l}\text { 7/17 (2 infection, } 1 \text { local pain, } 1 \text { wound dehiscence, } \\
1 \text { CSF leak, } 1 \text { local pain, } 1 \text { lead migration) }\end{array}$ \\
\hline
\end{tabular}

AFP = atypical facial pain; $\mathrm{CH}=$ cluster headache; $\mathrm{HA}$ = headache; IPG = implantable pulse generator; $\mathrm{PH}=$ postherpetic; PIFP = persistent idiopathic facial pain; $\mathrm{PS}$ = postsurgical; $\mathrm{PT}$ = posttraumatic; pts = patients; $\mathrm{SN}$ = supraorbital neuralgia; TDP = trigeminal deafferentation pain; $\mathrm{TMJ}$ = temporomandibular joint; TNP = trigeminal neuropathic pain; VAS = visual analog scale.

${ }^{*}$ PNFS and/or trigeminal ganglion stimulation.

† VAS score available in 13 patients.

toward the mean. However, at a median of 33 months, we report a comparatively long follow-up time with regular patient contact.

Although there have been several calls for randomized trials of PNFS in trigeminal neuralgia, a closer look at the reality of the situation bears little promise in achieving this goal. In the specific case of trigeminal neuralgia due to MS, the very low incidence of the disease is associated with major problems in terms of patient recruitment: in Northern Europe and North America, the incidence of MS has been reported to be anywhere between 7 and 20 cases per 100,000 persons. Given that only a minority of MS patients suffers from trigeminal neuralgia $\left(1.9 \%-6.3 \%^{16,32,37}\right)$, this incidence translates to approximately $0.13-1.26$ cases per 100,000 persons. Only a subgroup of these cases are refractory to medical treatment, and among those that are, many receive other treatments. Even considering trigeminal neuropathic pain of various etiologies would yield only a small number of patients available for a clinical trial, as a large variety of treatment options can be considered. Furthermore, given the rarity of the condition, device manufacturers have little incentive to invest in a controlled trial.

\section{Conclusions}

PNFS has been in use in the management of facial pain for over a decade, yet the evidence still does not exceed case series with short follow-up times and is thus unsatisfactory. It remains one of the options, among other treatments, to be individually considered for MS patients with refractory facial pain, as highlighted by our cohort observation. 


\section{Acknowledgments}

This work is part of a master's thesis of the Master's Program in Clinical Research, Center for Clinical Research and Management Education, Division of Health Care Sciences, Dresden International University, Dresden, Germany.

\section{References}

1. Amin S, Buvanendran A, Park KS, Kroin JS, Moric M: Peripheral nerve stimulator for the treatment of supraorbital neuralgia: a retrospective case series. Cephalalgia 28:355359,2008

2. Ariai MS, Mallory GW, Pollock BE: Outcomes after microvascular decompression for patients with trigeminal neuralgia and suspected multiple sclerosis. World Neurosurg 81:599-603, 2014

3. Asensio-Samper JM, Villanueva VL, Pérez AV, López MD, Monsalve V, Moliner S, et al: Peripheral neurostimulation in supraorbital neuralgia refractory to conventional therapy. Pain Pract 8:120-124, 2008

4. Barker FG II, Jannetta PJ, Bissonette DJ, Larkins MV, Jho HD: The long-term outcome of microvascular decompression for trigeminal neuralgia. N Engl J Med 334:1077-1083, 1996

5. Baschnagel AM, Cartier JL, Dreyer J, Chen PY, Pieper DR, Olson RE, et al: Trigeminal neuralgia pain relief after gamma knife stereotactic radiosurgery. Clin Neurol Neurosurg 117:107-111, 2014

6. Ben-Haim S, Mirzadeh Z, Rosenberg WS: Deep brain stimulation for intractable neuropathic facial pain. Neurosurg Focus 45(2):E15, 2018

7. Bender MT, Pradilla G, Batra S, See AP, James C, Pardo CA, et al: Glycerol rhizotomy and radiofrequency thermocoagulation for trigeminal neuralgia in multiple sclerosis. J Neurosurg 118:329-336, 2013

8. Broggi G, Ferroli P, Franzini A, Nazzi V, Farina L, La Mantia L, et al: Operative findings and outcomes of microvascular decompression for trigeminal neuralgia in 35 patients affected by multiple sclerosis. Neurosurgery 55:830-839, 2004

9. Carvalho C, Caetano JM, Cunha L, Rebouta P, Kaptchuk TJ, Kirsch I: Open-label placebo treatment in chronic low back pain: a randomized controlled trial. Pain 157:2766-2772, 2016

10. Cruccu G, Biasiotta A, Di Rezze S, Fiorelli M, Galeotti F, Innocenti $\mathrm{P}$, et al: Trigeminal neuralgia and pain related to multiple sclerosis. Pain 143:186-191, 2009

11. Dodick DW, Silberstein SD, Reed KL, Deer TR, Slavin KV, Huh B, et al: Safety and efficacy of peripheral nerve stimulation of the occipital nerves for the management of chronic migraine: long-term results from a randomized, multicenter, double-blinded, controlled study. Cephalalgia 35:344-358, 2015

12. Dunteman E: Peripheral nerve stimulation for unremitting ophthalmic postherpetic neuralgia. Neuromodulation 5:3237, 2002

13. Eldridge PR, Sinha AK, Javadpour M, Littlechild P, Varma TRK: Microvascular decompression for trigeminal neuralgia in patients with multiple sclerosis. Stereotact Funct Neurosurg 81:57-64, 2003

14. Ellis JA, Mejia Munne JC, Winfree CJ: Trigeminal branch stimulation for the treatment of intractable craniofacial pain. J Neurosurg 123:283-288, 2015

15. Feletti A, Santi GZ, Sammartino F, Bevilacqua M, Cisotto P, Longatti P: Peripheral trigeminal nerve field stimulation: report of 6 cases. Neurosurg Focus 35(3):E10, 2013

16. Hooge JP, Redekop WK: Trigeminal neuralgia in multiple sclerosis. Neurology 45:1294-1296, 1995

17. Jakobs M, Unterberg A, Treede RD, Schuh-Hofer S, Ahmadi
R: Subcutaneous trigeminal nerve field stimulation for refractory trigeminal pain: a cohort analysis. Acta Neurochir (Wien) 158:1767-1774, 2016

18. Johnson MD, Burchiel KJ: Peripheral stimulation for treatment of trigeminal postherpetic neuralgia and trigeminal posttraumatic neuropathic pain: a pilot study. Neurosurgery 55:135-142, 2004

19. Klein J, Sandi-Gahun S, Schackert G, Juratli TA: Peripheral nerve field stimulation for trigeminal neuralgia, trigeminal neuropathic pain, and persistent idiopathic facial pain. Cephalalgia 36:445-453, 2016

20. Klinger R, Kothe R, Schmitz J, Kamping S, Flor H: Placebo effects of a sham opioid solution: a randomized controlled study in patients with chronic low back pain. Pain 158:18931902, 2017

21. Kloimstein H, Likar R, Kern M, Neuhold J, Cada M, Loinig $\mathrm{N}$, et al: Peripheral nerve field stimulation (PNFS) in chronic low back pain: a prospective multicenter study. Neuromodulation 17:180-187, 2014

22. Krishnan S, Bigder M, Kaufmann AM: Long-term followup of multimodality treatment for multiple sclerosis-related trigeminal neuralgia. Acta Neurochir (Wien) 160:135-144, 2018

23. Lenchig S, Cohen J, Patin D: A minimally invasive surgical technique for the treatment of posttraumatic trigeminal neuropathic pain with peripheral nerve stimulation. Pain Physician 15:E725-E732, 2012

24. Magis D, Gerardy PY, Remacle JM, Schoenen J: Sustained effectiveness of occipital nerve stimulation in drug-resistant chronic cluster headache. Headache 51:1191-1201, 2011

25. Mallory GW, Atkinson JL, Stien KJ, Keegan BM, Pollock BE: Outcomes after percutaneous surgery for patients with multiple sclerosis-related trigeminal neuralgia. Neurosurgery 71:581-586, 2012

26. McMahon JT, Tora MS, Bentley JN, Texakalidis P, Campbell MA, Keifer OP Jr, et al: Percutaneous trigeminal nerve stimulation for persistent idiopathic facial pain: a case series. World Neurosurg 126:e1379-e1386, 2019

27. McRoberts WP, Wolkowitz R, Meyer DJ, Lipov E, Joshi J, Davis B, et al: Peripheral nerve field stimulation for the management of localized chronic intractable back pain: results from a randomized controlled study. Neuromodulation 16:565-575, 2013

28. Montano N, Papacci F, Cioni B, Di Bonaventura R, Meglio M: Percutaneous balloon compression for the treatment of trigeminal neuralgia in patients with multiple sclerosis. Analysis of the potentially prognostic factors. Acta Neurochir (Wien) 154:779-783, 2012

29. Mueller O, Diener HC, Dammann P, Rabe K, Hagel V, Sure $\mathrm{U}$, et al: Occipital nerve stimulation for intractable chronic cluster headache or migraine: a critical analysis of direct treatment costs and complications. Cephalalgia 33:12831291,2013

30. Narouze SN, Kapural L: Supraorbital nerve electric stimulation for the treatment of intractable chronic cluster headache: a case report. Headache 47:1100-1102, 2007

31. Przybylowski CJ, Cole TS, Baranoski JF, Little AS, Smith KA, Shetter AG: Radiosurgery for multiple sclerosis-related trigeminal neuralgia: retrospective review of long-term outcomes. J Neurosurg 131:1583-1590, 2019

32. Putzki N, Pfriem A, Limmroth V, Yaldizli O, Tettenborn B, Diener HC, et al: Prevalence of migraine, tension-type headache and trigeminal neuralgia in multiple sclerosis. Eur J Neurol 16:262-267, 2009

33. Rasche D, Tronnier VM: Clinical significance of invasive motor cortex stimulation for trigeminal facial neuropathic pain syndromes. Neurosurgery 79:655-666, 2016

34. Rogers CL, Shetter AG, Fiedler JA, Smith KA, Han PP, Speiser BL: Gamma Knife radiosurgery for trigeminal neu- 
ralgia: the initial experience of the Barrow Neurological Institute. Int J Radiat Oncol Biol Phys 47:1013-1019, 2000

35. Saper JR, Dodick DW, Silberstein SD, McCarville S, Sun M, Goadsby PJ: Occipital nerve stimulation for the treatment of intractable chronic migraine headache: ONSTIM feasibility study. Cephalalgia 31:271-285, 2011

36. Slavin KV, Wess C: Trigeminal branch stimulation for intractable neuropathic pain: technical note. Neuromodulation 8:7-13, 2005

37. Solaro C, Brichetto G, Amato MP, Cocco E, Colombo B, D'Aleo G, et al: The prevalence of pain in multiple sclerosis: a multicenter cross-sectional study. Neurology 63:919-921, 2004

38. Stidd DA, Wuollet A, Bowden K, Price T, Patwardhan A, Barker S, et al: Peripheral nerve stimulation for trigeminal neuropathic pain. Pain Physician 15:27-33, 2012

39. Tuleasca C, Carron R, Resseguier N, Donnet A, Roussel P, Gaudart J, et al: Multiple sclerosis-related trigeminal neuralgia: a prospective series of 43 patients treated with gamma knife surgery with more than one year of follow-up. Stereotact Funct Neurosurg 92:203-210, 2014

40. Velásquez C, Tambirajoo K, Franceschini P, Eldridge PR, Farah JO: Upper cervical spinal cord stimulation as an alternative treatment in trigeminal neuropathy. World Neurosurg 114:e641-e646, 2018

41. Verrills P, Rose R, Mitchell B, Vivian D, Barnard A: Peripheral nerve field stimulation for chronic headache: 60 cases and long-term follow-up. Neuromodulation 17:54-59, 2014

42. Weiner RL, Garcia CM, Vanquathem N: A novel miniature, wireless neurostimulator in the management of chronic craniofacial pain: preliminary results from a prospective pilot study. Scand J Pain 17:350-354, 2017
43. Yakovlev AE, Resch BE: Treatment of chronic intractable atypical facial pain using peripheral subcutaneous field stimulation. Neuromodulation 13:137-140, 2010

44. Zakrzewska JM, Linskey ME: Trigeminal neuralgia. BMJ 350:h1238, 2015

\section{Disclosures}

The authors report no conflict of interest concerning the materials or methods used in this study or the findings specified in this paper.

\section{Author Contributions}

Conception and design: Klein. Acquisition of data: Klein. Analysis and interpretation of data: Klein. Drafting the article: Klein. Critically revising the article: all authors. Reviewed submitted version of manuscript: all authors. Approved the final version of the manuscript on behalf of all authors: Klein. Statistical analysis: Klein. Study supervision: Klein.

\section{Correspondence}

Johann Klein: University Hospital Carl Gustav Carus, Technische Universität Dresden, Germany. johann.klein@ukdd.de. 